\title{
PHARMACOKINETICS OF MELATONIN IN PRETERM INFANTS
}

\author{
N. Merchant, D. Azzopardi, D. Edwards, Centre For Developing Brain \\ Neonatology, Imperial College London, MRC Centre for Clinical Sciences, London, UK
}

Background: There is strong experimental evidence of a neuroprotective effect of melatonin in immature animals. However, pharmacokinetic (PK) data on melatonin in preterm infants is lacking. The aim was to examine the preterm pharmacokinetic profile.

Methods: We conducted a multi centre, open label study in infants $<31$ weeks and $<7$ days of age. A single intravenous melatonin infusion was given to successive groups. Melatonin and its primary urinary metabolite aMT6s were analysed by radioimmunoassay. Dosage was adjusted in subsequent groups until adult physiological levels were achieved (34.5-1185.3 pmol/L).

Results: 18 preterms were enrolled. The results are summarized in table/graph below. Pre-infusion median plasma melatonin levels were $0 \mathrm{pmol} / \mathrm{L}$ (range- $0-165 \mathrm{pmol} / \mathrm{L}$ ). Blood melatonin levels closest to adult levels were achieved with a 2 hour infusion of $0.1 \mathrm{mcg} / \mathrm{kg} / \mathrm{hr}$; the half life was 15.99 hours and Area under the curve-7234.74. Lower doses resulted in widely variable PK data.

\begin{tabular}{|l|l|l|l|}
\hline Dose & Time (Hours) & Urine aMT6S $(\mathrm{ng} / \mathrm{ml})$ & Range aMT6S (ng/ml) \\
\hline $0.1 \mathrm{mcg} / \mathrm{kg} / \mathrm{hr}$ for 6 hours & $0,2,4,6$ & $0.8,2.1,0.6,0.4$ & $0-0.8,0-3.7,0-1.1,0-0.8$ \\
\hline \hline $0.1 \mathrm{mcg} / \mathrm{kg} / \mathrm{hr}$ for 2 hours & $0,2,4,6$ & $0.9,0.8,0.6,1.3$ & $\begin{array}{l}0.8-1.0,0.8-0.8,0.6- \\
0.6,0.7-2.4\end{array}$ \\
\hline
\end{tabular}

[Urine aMT6S profile]

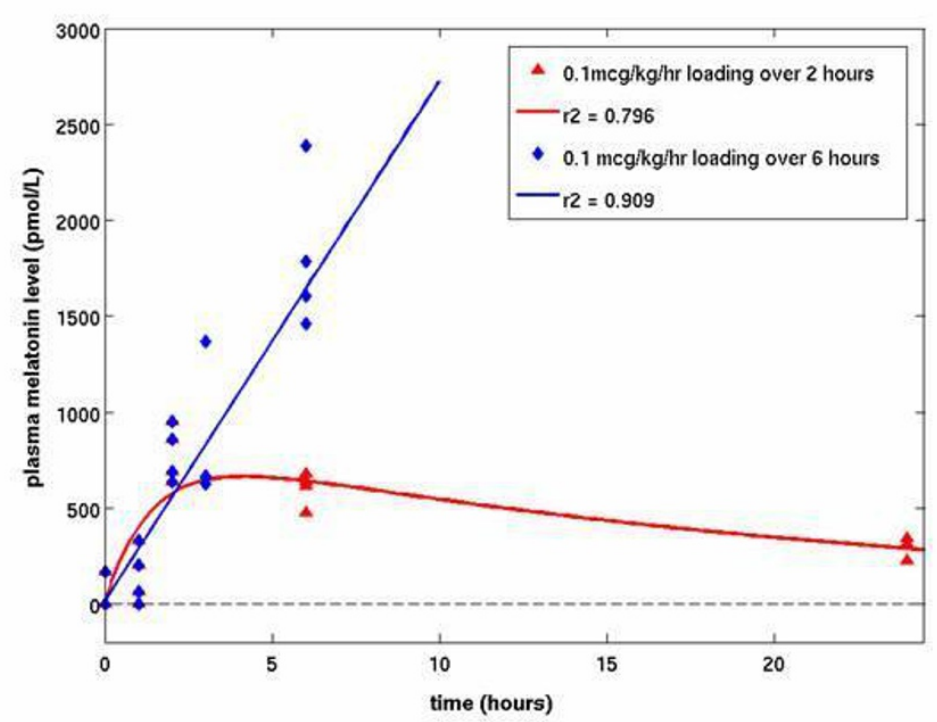

[Plasma Melatonin Profile]

Conclusion: Preterms have none or minimal circulating plasma melatonin. Urinary aMT6s levels are negligible in this gestational age group, probably because of immature liver metabolism. This melatonin PK data will be used in future clinical studies to test the hypothesis that melatonin has a neuroprotective effect. 